\title{
A teoria da atividade na organização do ensino de Matemática com o computador portátil
}

\author{
Rodrigo Lacerda Carvalho \\ Universidade Federal do Cariri (UFCA) \\ rodrigo.lacerda@cariri.ufc.br

\section{Marcilia Chagas Barreto} \\ Universidade Estadual do Ceará (UECE) \\ marcilia_barreto@yahoo.com.br
}

\begin{abstract}
Resumo
As tecnologias digitais estão presentes na escola, assim, são imprescindíveis estudos que indiquem como melhor utilizá-las no ensino de Matemática. Então, o nosso objetivo, neste trabalho, é analisar a percepção e a prática de um professor de Matemática em relação ao uso do laptop educacional para o ensino da referida disciplina. Como aporte teórico utilizamos a Teoria da Atividade visando à transformação da atividade de ensino em aprendizagem. Como metodologia, foram utilizados alguns elementos da pesquisa colaborativa. Evidenciamos que o laptop educacional estava sendo pouco utilizado e, posteriormente, constatamos o avanço do seu uso pelo professor na organização do ensino de função afim.
\end{abstract}

Palavras-chave: Ensino de Matemática. Laptop Educacional. Teoria da Atividade. Pesquisa Colaborativa.

\section{The activity theory at the organization of teaching Mathematics with portable computer}

\begin{abstract}
Digital technologies are present in school, thus are essential studies to indicate how best to use them at teaching Mathematics. Then, our aim on this paper is to analyze the perception and the practice of a math teacher in relation to the use of educational laptop for teaching this discipline. As a theoretical contribution we use the Activity Theory aiming to transform the learning activity in learning. As a methodology, we use some elements of collaborative research. We realize that educational laptop was being few used and posteriorly we noticed the advance of its use by the teacher at the organization of the teaching of affine function.
\end{abstract}

Keywords: Teaching Mathematics. Educational laptop. Activity Theory. Collaborative Research. 


\section{Introdução}

Nas últimas décadas, o poder público investiu fortemente na informatização das escolas brasileiras, visando à melhoria do processo de ensino e aprendizagem. Dessa forma, a presença dos computadores na escola não se restringe apenas à implantação de laboratórios de informática, e sim na proposta que prevê um equipamento, como laptops ou tablets, para cada aluno.

Entretanto, a introdução de recursos tecnológicos nas escolas não garante, per si, uma mudança no desempenho dos estudantes, também não aperfeiçoa as práticas pedagógicas. Portanto, as Tecnologias Digitais de Informação e Comunicação (TDIC) devem ser integradas ao currículo escolar para proporcionar experiências pedagógicas para o aprendizado de conteúdos disciplinares diferentes das “outras” tecnologias, tradicionalmente, usadas na escola (VALENTE, 2011).

Para tanto, é fundamental a formação de professores para o uso adequado das TDIC para o processo de ensino e aprendizagem. É imperativo discutir sobre as dificuldades que professores têm em utilizar essas tecnologias. Esta realidade demanda um olhar atento daqueles que fazem educação e de pesquisas empíricas que possam afirmar ou desmistificar a importância de determinados recursos na prática pedagógica.

Nesta pesquisa, direcionamos nossas reflexões ao uso das TDIC no ensino da Matemática. Especificamente do laptop educacional, do Projeto Um Computador por Aluno (UCA), para o ensino de função afim. O Projeto UCA estima para cada estudante, professor e gestor de escolas públicas brasileiras um laptop para ser utilizado no contexto escolar e se propõe também de intervenção, pois forma professores e gestores visando à incorporação desses recursos, de fato, à dinâmica da escola.

Os referidos laptops oportunizam a convergência de outras mídias, por exemplo, imagem, áudio, vídeo, que lhes confere o aspecto multimidiático. Importa que os professores tenham ciência dessa característica única destes instrumentos, em relação às demais tecnologias disponíveis nas escolas, para pensar de que maneira isso pode estar a serviço de sua prática docente. Convém registrar que tal ação é, também, uma forma de repensar o ensino da Matemática e o uso das tecnologias na Educação Básica. Como afirmam Fiorentini e Lorenzato (2009, p. 46):

Parece haver uma crença, entre alguns responsáveis pelas políticas educacionais, de que as novas tecnologias são uma panaceia para solucionar os males da educação atual. Essa é uma razão pela qual a comunidade de EM [Educação Matemática] deve investigar seriamente a implementação e utilização das TICs, pois, se, de um lado, pode ser considerado relativamente simples equipar as escolas com essas tecnologias, de outro, isso exige profissionais que saibam utilizá-las com eficácia na prática escolar.

Nesse sentido, o computador, conectado à internet, é um recurso que pode potencializar o ensino de Matemática e consequentemente despertar no aluno a necessidade de aprender essa 
disciplina. Partindo dessa concepção e visando a perceber formas mais efetivas com o uso deste recurso, utilizaremos como aporte teórico a Teoria da Atividade, que será discutida no tópico a seguir.

Assim, este trabalho tem como objetivo analisar a percepção e a prática de um professor de Matemática em relação ao uso laptop educacional para o ensino dessa disciplina. Convém ressaltar que o presente trabalho é um recorte de nossa dissertação de Mestrado. Para tanto, o método de pesquisa que utilizamos foram alguns elementos da Pesquisa Colaborativa (TELES; IBIAPINA,2009)

A característica desse método de investigação é que ele não se interessa apenas pela natureza do trabalho desenvolvido pelo professor, mas igualmente pela formulação de alternativas de formação em serviço. Três caminhos distintos que se complementam estão na operacionalização metodológica da pesquisa: a co-situação, a co-operação e a co-produção. Para Fiorentini e Lorenzato (2009), o prefixo co significa ação conjunta. Assim, neste trabalho, iremos tratar da primeira e da segunda etapas deste método de pesquisa.

$\mathrm{Na}$ co-situação, ocorrem as negociações e a inserção em um projeto que visa a contribuir para a construção de saberes tanto para a comunidade escolar quanto para a científica. Nesta fase, realizamos a aproximação com a escola e com o professor participante da pesquisa, com a intenção de levantar demandas formativas dos envolvidos.

A co-operação é a fase do processo de formação, de observação das aulas e de explicitação dos diálogos entre o pesquisador e o professor envolvidos na pesquisa. Neste artigo, focamos o momento da observação das aulas do conceito de função afim com o uso do laptop educacional.

No próximo tópico, abordaremos os conceitos referentes à Teoria da Atividade, que fundamentaram nossa análise, e discutiremos também a inserção destas tecnologias no ensino e na aprendizagem da Matemática.

\section{Os fundamentos da Teoria da Atividade na organização do ensino de Matemática com laptop educacional}

A teoria da atividade foi desenvolvida por Leontiev e tem raiz histórico-cultural na psicologia soviética. Assim, pode ser considerada um desdobramento dos postulados de Vygotsky, especialmente nas questões pautadas na relação homem-mundo, construída historicamente e mediada por instrumentos.

De acordo com Leontiev (2010, p.68), “por atividade, designamos os processos psicologicamente caracterizados por aquilo a que o processo, como um todo, dirige-se (seu objeto), coincidindo sempre com o objetivo que estimula o sujeito a executar esta atividade, isto é, o motivo." 
A ação é o componente principal da atividade, porque uma atividade será desenvolvida por meio da ação. Na verdade, por meio de uma ou de várias, porém

... o objetivo de uma ação, por si mesma, não estimula a agir. Para que a ação surja e seja executada é necessário que seu objetivo apareça para o sujeito, em sua relação com o motivo da atividade da qual ele faz parte. Além disso, esta relação também é refletida pelo sujeito de uma forma bastante precisa, a saber, na forma de conhecimento do objeto de ação como um alvo. O objeto de uma ação é, por conseguinte, nada mais que seu alvo direto reconhecido. (LEONTIEV, 2010, p. 69).

Ainda de acordo com Leontiev (2010), as formas de realização da ação são denominadas operações, que são os meios, mediante os quais se realiza uma ação. As ações estão relacionadas aos objetivos, e as operações relacionam-se às condições de executar esses objetivos. Podemos elencar, como exemplo, os estudantes podem utilizar o laptop educacional como uma operação para conseguir a ação de compreender o conceito de função afim.

Uma ação pode realizar-se por meio de diferentes operações, ao passo que ações diferentes podem ser realizadas pelas mesmas operações (LOPES, 2009). No caso da apropriação do conceito de função afim por parte do estudante, por exemplo, o professor pode realizar esta ação por meio de diferentes operações: além do uso da linguagem, ele pode utilizar o laptop educacional, o livro didático e a resolução de exercícios. Em síntese, o docente irá recorrer às condições que lhe sejam mais favoráveis para atingir o seu objetivo.

As categorias da teoria: atividade - ação - operação que, por sua vez, são correlacionáveis à necessidade/motivo - objetivos - condições para realizar os objetivos não são estanques. A ação pode transformar-se em uma operação ou elevar-se a uma atividade, no primeiro caso, Leontiev (2010) destaca que, nesta relação, um aspecto importante é que, na transformação de uma ação em operação, fica explícita a ideia de desenvolvimento. É também uma forma do professor identificar que conseguiu levar o estudante à aprendizagem de um novo conceito. Na segunda situação, uma ação que, em princípio, era realizada apenas como parte de uma atividade pode passar a ter para o sujeito um motivo em si. A ideia de seu movimento é uma grande contribuição de Leontiev (2010) para o ensino.

As contribuições dessa perspectiva teórica para a organização do ensino de Matemática se dá de modo que os conteúdos desta área do saber sejam trabalhados, oportunizando aos estudantes a apropriação teórica dos conceitos matemáticos. Assim, passando a perceber a Matemática como uma atividade do ser humano na produção e na apropriação dos seus saberes.

Nessa perspectiva, o ensino de Matemática, a partir das TDIC, pode proporcionar aos estudantes não apenas uma nova maneira de estudar temas tradicionais, mas de trabalhar novos temas gerando uma necessidade de aprender. Uma das potencialidades do uso do computador no ensino da Matemática é a elaboração e comprovação de hipóteses a partir de recursos 
multimidiáticos, como softwares educativos e objetos educacionais (OE). Tais recursos oportunizam aos aprendizes condições favoráveis para o entendimento e para a produção de gráficos, fazer cálculos, realizar análises e construções geométricas planas ou espaciais, dentre outros conceitos.

As categorias da Teoria da Atividade - ações e operações - podem ser vistas como organizadoras do ensino em sala de aula, com uma visão articulada entre os motivos que impulsionam os sujeitos a agir, os objetivos delimitados nas ações e os meios que são as operações. Ao compreendermos esta articulação, é possível perceber se uma aula de Matemática, utilizando o laptop, produz em nossos alunos a motivação necessária para atingir os objetivos propostos.

Nesse contexto, Borba e Penteado (2010) enfatizam que o computador deve estar inserido ao cotidiano da sala de aula em atividades essenciais, como contar, entender gráficos e desenvolver noções espaciais. Mendes (2009, p. 113) afirma que "o computador exerce um papel decisivo no ensino da Matemática, nos dias atuais, em virtude das possibilidades de construção de modelos virtuais para a Matemática imaginária”.

Isso é o que demonstra a pesquisa de Maia, Carvalho e Castro Filho (2013), que revela que a utilização de ambientes computacionais, mediada pela intervenção do professor, proporciona aos discentes desenvolverem uma melhor compreensão dos conteúdos matemáticos, especificamente do conceito de função.

Nessa perspectiva, por meio da mediação social e de instrumentos, a escola pode levar o sujeito ao conhecimento. A Teoria da Atividade nos ajuda a perceber a importância da inserção do sujeito em um ambiente rico de experiências que lhe fornecerá base empírica, a qual poderá ser trabalhada no ambiente escolar, em busca da elaboração do conhecimento científico.

Com a chegada dos laptops educacionais aos sistemas escolares, o uso do computador torna-se uma prática corrente da cultura da sala de aula, podendo ser utilizado por professores e alunos a qualquer momento, como uma ferramenta para potencializar o conhecimento. No modelo 1:1 (um para um), cada aluno tem, à sua disposição, um equipamento computacional com conexão à internet e mobilidade que permite que o recurso seja integrado ao ambiente de sala de aula e, inclusive, fora dela (VALENTE, 2011).

No próximo tópico, procederemos com a análise dos dados, referentes às fases de cosituação e co-operação, sempre buscado uma articulação concreta entre a Teoria da Atividade e os aspectos observados a partir das vivências pedagógicas durante a pesquisa empírica. 


\section{Análise dos dados}

\section{Co-situação}

Nesta fase, debatemos com o professor participante da pesquisa acerca do contexto do ensino de Matemática, suas dificuldades e possibilidades, diante do computador portátil presente em sala de aula.

Assim, destacamos um momento que explicita a percepção do professor de Matemática em relação ao uso do laptop educacional em sala de aula.

\section{O professor justificando porque utiliza pouco o laptop educacional}

Conheço a parte de hardware do computador, mas, em relação aos softwares, não conheço quase nenhum recurso digital para se trabalhar com o ensino de Matemática. Além disso, o laptop educacional tem pouca memória, e a tela é muito pequena.

Constatamos que o laptop educacional estava sendo pouco utilizado, devido a algumas de suas limitações, como a baixa memória para fazer download. Para este problema, foi sugerida a alternativa de trabalhar com os softwares direto da internet, sem precisar baixá-los ou escolher OE, escritos em linguagem de programação flash e que ocupam menos espaço no computador. Quanto à tela ser pequena, realmente, é um fato, porém temos que aproveitar o recurso que está disponível. No caso dos OE, tais recursos ficam adaptados ao tamanho da tela, isso pode melhorar sua utilização.

Entretanto, é evidente, na fala do professor, que o maior motivo da pouca utilização do computador se devia ao fato de quase não conhecer softwares para o ensino de Matemática. A partir dessa realidade, em momentos de planejamento das aulas realizados pelo professor e pelo pesquisador, exploramos recursos interativos para se trabalhar função afim, conteúdo explorado pelo docente durante a pesquisa. Dentre esses recursos apresentados, estavam OE Primeiro, Aprender! Digital e Grande Prêmio Funcional, disponíveis no site do Grupo de Pesquisa e Produção de Ambientes Interativos e Objetos de Aprendizagem (PROATIVA) da Universidade Federal do Ceará (UFC) e o software educativo livre GeoGebra. Neste artigo, para nossa análise, selecionamos o recurso GP Funcional, que é um OE desenvolvido pelo PROATIVA e que trabalha as representações algébrica e gráfica da função afim.

$\mathrm{O}$ uso de softwares educativos, que geram gráficos a partir de tabelas e expressões algébricas, manipuladas de forma interativa pelo usuário, desvelam novas possibilidades para o ensino da Matemática. Nesse sentido, Moura (2002) relata que uma adequada organização das atividades de ensino leva o professor a reconhecer as particularidades do desenvolvimento da 
Matemática. Isto poderá ser concretizado em atividades de ensino que nascem de uma necessidade de aprender desencadeada por situações-problema que possibilitem os sujeitos agirem como solucionadores de problemas: definindo ações, escolhendo os dados e fazendo uso de ferramentas que sejam adequadas para a solução da situação posta.

A percepção das TDIC, por vezes, dá relevo à máquina (hardware) em detrimento dos recursos digitais (softwares) utilizados por meio deles. Nesse caso, observamos que o professor tinha essa carência formativa, fundamental para o trabalho pedagógico. Isto corrobora ao que sugere Mendes (2009): as TDIC como suporte também para o professor. A seguir, analisaremos o momento da co-operação.

\section{Co-operação}

Nesta fase da pesquisa, cada aula foi planejada em conjunto - pesquisador e professor - visando à motivação em sala de aula para que os estudantes se tornassem investigadores do conceito de função afim, sempre tomando por base as categorias da Teoria da Atividade; em seguida, dava-se a observação da aula e o registro dos elementos no diário de campo; finalmente, realizava-se a reflexão acerca do momento considerado mais importante pelo professor e pelo pesquisador.

Teles e Ibiapina (2009) afirmam que este momento de operação conjunta aproxima a pesquisa científica da escola, logo, viabiliza a aproximação entre teoria e prática. Este modelo de pesquisa dá destaque à prática, na formação dos participantes e na produção do conhecimento científico, além de possibilitar, entre outras situações, o envolvimento do professor e do pesquisador no processo de construção do conhecimento. Dada a profusão de dados coletados, selecionamos para este trabalho um episódio de ensino, que será analisado a seguir.

\section{O conceito de gráfico da função afim por meio do OE GP Funcional}

O professor iniciou a aula explicitando os objetivos - ou ações - para os alunos, quais sejam: a) identificar a representação algébrica e gráfica da função afim; e b) reconhecer, por meio do gráfico, uma função afim: crescente, decrescente e constante. Após este momento, o docente abordou como instrumento os fundamentos históricos sobre o desenvolvimento do conceito de função, para trazer à tona questões sobre a necessidade da humanidade em relacionar grandezas variáveis, por exemplo, a velocidade e o tempo. Abordou também a Geometria Analítica como fundamental para o desenvolvimento do conceito de funções. Nesse sentido, o professor percorreu um caminho, considerando o conhecimento como produto da atividade humana (MOURA et al, 2010).

Após esta exposição, o docente pediu aos alunos que acessassem o GP Funcional. Notemos 
que o professor continua valorizando a aula expositiva, pois, somente depois, ele fala sobre a utilização do laptop. Posteriormente, solicitou aos estudantes que se dividissem em quatro equipes, entrassem na opção "conhecendo os coeficientes" do OE, para manipularem livremente os coeficientes $a$ e $b$ e discutissem como o gráfico se comportava. Em seguida, sugeriu que cada equipe relatasse diferentes situações observadas.

Percebemos que o professor visa a estimular a colaboração e a participação dos estudantes. Nesse sentido, o docente, ao desenvolver suas ações, percebe a necessidade de momentos de produções em grupos e de socializações de tais produções como estratégias que criam condições para que se estabeleçam mediações necessárias entre alunos e conhecimento de forma que se dê a aprendizagem por meio das apropriações que os sujeitos estabelecem sobre conhecimentos que são construções sócio-históricas (MORETTI, 2007).

O professor passa pelos grupos para orientar os estudantes. As intervenções nos grupos passam a ser no sentido de discutir o movimento da reta em diferentes situações. Assim, o docente leva os alunos a refletirem sobre suas ações no OE. Por isso, o professor realiza diversos questionamentos, tanto para verificar se os alunos estão compreendendo o movimento da reta como para exigir que eles explicitem as razões de suas ações, envolvendo-os em um movimento reflexivo que objetiva conduzir à tomada de consciência da própria ação.

Com essa mediação, o professor buscou garantir o movimento indivíduo-coletivo das soluções apresentadas, ao passo que proporcionou uma experiência de aprendizagem de cunho sócio interacionista (VYGOTSKY, 2002), oportunizando aos estudantes o trabalho em grupo, mediatizado por ferramentas tecnológicas. Ao compartilhar e articular ideias, os alunos podem ensinar uns aos outros e assim construírem seus conceitos. Nesse caso, o OE fomentou o levantamento, a troca, a experimentação (BORBA; PENTEADO, 2010) e a partilha de ideias pelos aprendizes. Após experimentações e discussões entre os grupos, constatamos que o professor conseguiu produzir uma motivação nos alunos, criando uma efetiva necessidade de aprender o conteúdo. Nesse contexto, apresentaremos o momento de socialização das soluções encontradas por cada equipe.

Quando o valor de a é positivo, a reta fica para cima. (Equipe 1)

Quando o valor de a é negativo, a reta fica para baixo. (Equipe 2)

O gráfico de uma função afim sempre é uma reta. (Equipe 3)

Quando o valor de a é igual a zero, a reta é paralela ao eixo x. (Equipe 4)

Segundo Leontiev (2010), a consciência da própria ação é tão importante quanto a ação. Para Vygotsky (2002), a tomada de consciência e a apreensão são formações essenciais na idade escolar, sob as quais giram todas as funções básicas envolvidas na aprendizagem. A consciência da ação é uma capacidade que influencia a realização da generalização. A seguir, apresentamos o que 
os estudantes produziram, em equipes, no GP Funcional.

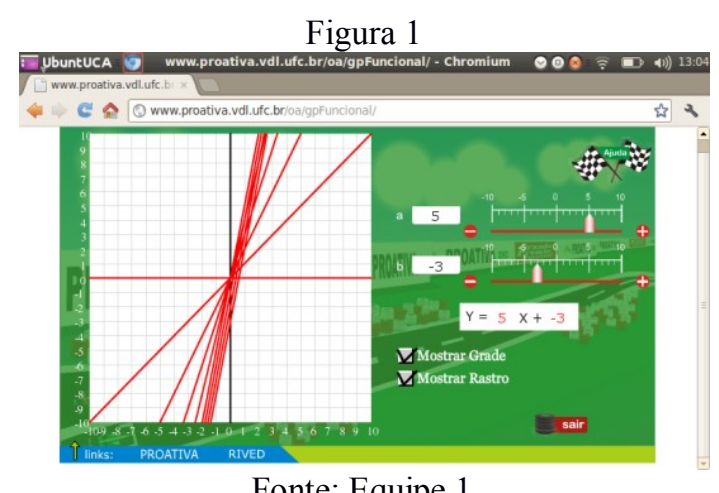

Fonte: Equipe 1

Figura 2

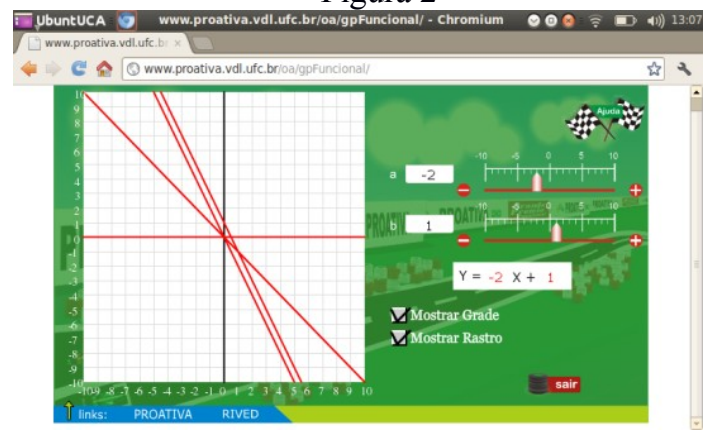

Fonte: Equipe 2
Figura 3

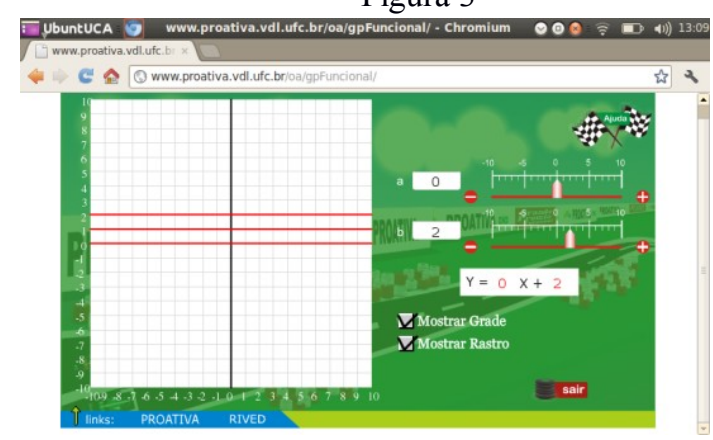

Fonte: Equipe 4

Evidenciamos que, manipulando o $\mathrm{OE}$, as equipes conseguiram compreender os conceitos em estudo. Outra vantagem do recurso é que os alunos puderam visualizar o rastro da reta desde a origem até chegar à função algébrica indicada, pois esta tarefa torna-se impossível com a utilização do lápis e papel. No momento de socialização, os estudantes tomam consciência de suas próprias ações. Mesmo o professor julgando que os alunos deram respostas coerentes, continua a questionálos. Dessa forma, evita-se que, sob a afirmação de cada equipe, esteja oculto um ato mecânico, sem significado conceitual para o indivíduo.

Quando o valor de a é positivo, por que a reta fica para cima? (Professor) Por que o valor de a vai sempre crescer, a função é crescente. (Equipe 1)

O professor repete a resposta da equipe 1 com um questionamento e consegue que os alunos formalizem um tipo de função afim, a crescente. Os alunos partiram de um caso geral de função afim e chegaram a um caso específico, a função afim crescente. De acordo com Davydov (1982), este é o caminho ideal para a aprendizagem conceitual. A equipe 2 fica eufórica, vibra bastante com a resposta da primeira equipe e formaliza também o seu conceito.

Então, quando o a é negativo, a função é decrescente! Muito massa! (Equipe 2)

Observamos que, em momento algum, o professor disse as características dos tipos de função. Esses conceitos foram compreendidos pelos alunos com a inter-relação no recurso, entre eles e com a mediação do professor. Nessa perspectiva, a interação social é fundamental para a 
aprendizagem de novos conceitos.

Como se pode perceber, utilizando o laptop educacional, o professor partiu da ação para chegar à formalização, assim, como geralmente acontece com as descobertas matemáticas. A equipe 3 chegou à conclusão de que a curva do gráfico de uma função afim sempre será uma reta; o quarto grupo concluiu que, quando o valor do coeficiente $a$ é igual a zero, a reta é paralela ao eixo $x$.

De acordo com Ferraz e Gitirana (2007), em uma primeira abordagem de gráficos de funções, o método de manipular livremente gráficos é importante para que o aluno possa ter a ideia da curva que representa o gráfico da função. Para cada família de função, há um tipo de curva geométrica que corresponde a seu gráfico. Isto é importante que seja percebido pelos estudantes, como neste caso, para que não haja uma mecanização da atividade.

Ao docente coube mediar a descoberta dos alunos. Tanto que, depois de mais debates, os integrantes da equipe 4 chegaram à conclusão de que o coeficiente $\underline{a}$, no gráfico, significa a inclinação da reta; a equipe 2 complementou que, no gráfico, o coeficiente $b$ sempre corta o eixo $y$, ou seja, no ponto em que a reta tocar em $y$, corresponderá ao valor de $b$.

Portanto, concluímos que, com essas situações, os discentes, de forma autônoma, compreenderam que: a) a curva do gráfico de uma função afim sempre é uma reta; b) quando o coeficiente $a$ é positivo ( $a>0$ ), a função é crescente, quando for negativo $(a<0)$, será decrescente, e, quando $a$ for igual a zero, a reta será paralela ao eixo $x$; e c) que a reta cruza o eixo $y$ no valor de $b$.

Nesse momento, os estudantes também refletem e generalizam situações. Elencamos, como exemplo, a atividade de livre manipulação do OE; o momento de desenvolvimento das ações de elaboração dos conceitos sobre a posição da reta no gráfico da função afim; e a discussão desses momentos como oportunidade de socializar o conhecimento e tomar consciência das ações. A partir do exposto, podemos considerar que a atividade de ensino levou os discentes à aprendizagem.

\section{Considerações finais}

O avanço constatado na prática do professor participante da pesquisa no decorrer da investigação revela que o docente, em vários momentos, levou os estudantes à aprendizagem do conceito de função afim, além de mostrar que a formação é fundamental na inserção das tecnologias na educação.

Constatamos que a Teoria da Atividade contribuiu na organização do ensino do conteúdo de função afim com o uso do laptop. Nesta perspectiva, na apropriação do conhecimento matemático, o professor agiu intencionalmente de forma a criar condições desencadeadoras para a aprendizagem. A referida teoria auxiliou o professor na geração de atividade em sala de aula, ou seja, criou nos alunos uma verdadeira necessidade de aprender. 
As constatações empíricas da co-situação revelaram que o professor apresentava lacunas referentes a usar o computador pedagogicamente no ensino de Matemática. Na co-operação, constatamos o avanço do professor ao utilizar a Teoria da Atividade na organização do ensino de funções e uma melhor concepção de como utilizar o laptop educacional no ensino deste conteúdo.

Nas situações desencadeadoras de ensino com o uso do laptop educacional, evidenciamos que este cenário potencializa o ensino de Matemática, pois, a partir de então, os alunos reconheceram que a curva do gráfico de uma função afim é uma reta. Os estudantes também articularam as definições de função crescente, decrescente e constante e os registros de representação algébrica e gráfica, que foi um aspecto fundamental para que a atividade de ensino acontecesse de maneira a levar os estudantes à aprendizagem.

\section{Referências}

BORBA, M. de C.; PENTEADO, M. G. Informática e Educação Matemática. 4 ${ }^{\mathrm{a}}$ ed. Belo Horizonte: Autêntica Editora, 2010.

DAVYDOV, V.V. Tipos de generalizacion em la ensenanza. Habana: Editorial Pueblo y Educacion, 1982.

FERRAZ, A.G.; GITIRANA, V. Uma análise do esboço de gráficos de função em livros textos de cálculo diferencial e integral. In: Anais do IX Encontro Nacional de Educação Matemática. Belo Horizonte, 2007.

FIORENTINI, D.; LORENZATO, S. Investigação em educação matemática: percursos teóricos e metodológicos. 3. ed. rev. - Campinas, SP: autores Associados 2009.

LEONTIEV, A. N. Uma Contribuição à Teoria do Desenvolvimento da Psique Infantil. In : Vigotski ,L. S. Linguagem, Desenvolvimento e Aprendizagem. Tradução de Maria da Pena Villalobos. 11 $1^{\mathrm{a}}$ edição-São Paulo: Ícone, 2010.

LOPES, A.R.L.V. Aprendizagem da docência em matemática: o Clube de Matemática como espaço de formação inicial de professores. Passo Fundo: Ed. Universidade de Passo Fundo, 2009.

MAIA, D. L..; CARVALHO, R. L.; CASTRO FILHO, J. A. de. O laptop educacional no ensino de função: experiência de aprendizagem colaborativa com suporte computacional. In: BARRETO, M. C.; PINHEIRO, J. L.; CARVALHO, R. L.; MAIA, D. L. Matemática, aprendizagem e ensino. Fortaleza: EdUECE, (2013).

MENDES, I. A. Matemática e investigação em sala de aula: tecendo redes cognitivas na aprendizagem. Ed. rev. e aum. São Paulo: Editora Livraria da Física, 2009.

MORETTI, V. D. Professores de matemática em atividade de ensino: uma perspectiva históricocultural para a formação docente. 2007. 207f. Tese (Doutorado). Faculdade de Educação. Universidade de São Paulo, São Paulo, 2007.

MOURA, M. O.; ARAÚJO, E. S.; RIBEIRO, F. D.; PANOSSIAN, M. L.; MORETTI, V. D. A Atividade Orientadora de Ensino como Unidade entre Ensino e Aprendizagem. In: A atividade pedagógica na teoria Histórico-Cultural. Organizado por Manoel Oriosvaldo de Moura Brasília : Liber livro, 2010. 
. A atividade de ensino como ação formadora. In: CASTRO, A. D.; CARVALHO, A. M. P. de (Org.). Ensinar a ensinar: didática para a escola fundamental e média. São Paulo: Pioneira Thompson, 2002.

TELES, F. P.; IBIAPINA, I. M. L. M. A pesquisa colaborativa como proposta inovadora de investigação educacional. In: Diversa. Ano 2 - nº 3 :: jan./jun. 2009.

VALENTE, J. A. Um laptop para cada aluno: promessas e resultados. In: ALMEIDA, M. E. B. de; PRADO, M. E. B. B.(Orgs.). O computador portátil na escola: mudanças e desafios nos processos de ensino e aprendizagem. São Paulo: AVERCAMP, 2011.

VYGOTSKY, L. S. A formação social da mente. 6. Ed. São Paulo:Martins Fontes, 2002.

Submetido em fevereiro de 2014

Aprovado em outubro de 2014 